\title{
ANÁLISE DE CHISTES REFERENTES À MULHER: UM ESTUDO À LUZ DE CONCEITOS PRECONIZADOS POR MARCELO DASCAL EM INTERPRETAÇÃO E COMPREENSÃO
}

\author{
WILZA KARLA LEÃO DE MACEDO (UNISC) ${ }^{1}$ \\ https://orcid.org/0000-0002-6909-6376
}

\begin{abstract}
RESUMO: Este artigo analisa três chistes referentes à mulher em contextos políticos, a partir de diferentes personagens públicas. Trata-se de um estudo interdisciplinar que apresenta o conceito de chiste de acordo com Freud (1996) e Dascal (2006), analisando os enunciados a partir de recursos sociopragmáticos. A interpretação feita baseou-se em estudos da interpretação/compreensão leitora, indiretividade e implicitude sociopragmática da linguagem e definiu o seu escopo, segundo preconiza a pragmática, delimitando o conceito de contexto e de intenções comunicativas de acordo com Dascal. Apresenta o que defende Dascal (2006) sobre a relação complementar entre a semântica e a pragmática, em sentido de cooperação, em domínios paralelos e complementares. Discute a ideia dascaliana, na qual a pragmática não priva a semântica das suas tarefas, todavia, amplia o âmbito das suas responsabilidades, assim, o contexto não se caracteriza como um fenômeno pragmático em distinção ao semântico. Estando na base de outros tipos de informação contextual, a pragmática se encarrega de verificar a correspondência entre a proposição expressa pela elocução e a intenção comunicativa do falante. Logo, no artigo, o contexto é discutido como elemento com funções diferentes - uma semântica e outra pragmática, conforme Dascal (2006). As análises foram uma tentativa de aplicação da teoria freudiana e dascalina a atos de fala cotidianos, buscando atestar que o estudo de linguagem é interdisciplinar e multifacetado.
\end{abstract}

PALAVRAS-CHAVE: Chiste. Interpretação. Compreensão leitora. Contexto. Intenção comunicativa.

ABSTRACT: This article examines three jokes referring to women in political contexts. It is an interdisciplinary study that introduces the concept of joke according to Freud (1996) and Dascal (2006). Statements are analysed from the perspective of sociopragmatic resources. The analysis was based on studies of reading interpretation/comprehension, indirectiveness and language sociopragmatic implicitude which defines its scope, according to pragmatics, delimiting the notion of context and communicative intention in accordance with Dascal. It presents what Dascal (2006) defends about the complementary relationship between semantics and pragmatics, in the sense of cooperation, in parallel and complementary domains. It discusses the Dascalian idea, in which pragmatics do not deprive the semantics of its tasks, however, it broadens the scope of its responsibilities, thus, the context is not characterized as a pragmatic phenomenon in distinction to semantics. Based on other types of contextual information, pragmatics is responsible for verifying the correspondence between the proposition expressed by the utterance and the communicative intention of the speaker. Therefore, in the article, the context is discussed as an element with different functions - one semantic and the other pragmatic, according to Dascal (2006). The analyzes were an attempt to apply the Freudian and dekaline theory to everyday speech acts, seeking to attest that the language study is interdisciplinary and multifaceted.

KEYWORDS: Joke. Interpretation. Reading comprehension. Context. Communicative intention.

\footnotetext{
${ }^{1}$ Doutoranda no Programa de Pós-Graduação em Letras da Universidade de Santa Cruz do Sul (UNISC), Rio Grande do Sul. E-mail: wilzaleao@hotmail.com
} 


\section{$=$ TRAMA $=$}

\section{INTRODUÇÃO}

A proposta de Dascal (2006) sustenta que a semântica e a pragmática têm uma relação mais complementar do que residual. Para ele, "a pragmática e a semântica trabalham juntas, em domínios paralelos e complementares, cooperando, e não lutando” (DASCAL, 2006, p. 35), assim, a pragmática não priva a semântica das suas tarefas, ao contrário, aumenta o âmbito das suas responsabilidades. Considerando-se a determinação das condições de verdade de um "pensamento" expresso em uma sentença como uma das tarefas da semântica, é preciso acrescentar, assegura Dascal, que esta não se restrinja ao significado da sentença por ser este insuficiente para determinar as condições de verdade, requerendo a inclusão do significado da elocução em seu âmbito. Essa ponderação esclarece que o contexto não se caracteriza como um fenômeno pragmático em distinção ao semântico. A ideia é que, estando na base de outros tipos de informação contextual, a pragmática se encarrega de verificar a correspondência entre a proposição expressa pela elocução e a intenção comunicativa do falante. "O contexto possui, portanto, funções diferentes - uma semântica e outra pragmática - que não devem ser confundidas" (DASCAL, 2006, p. 35).

Assim, enquanto a semântica descreve e analisa os significados habituais, explícitos, as intenções comunicativas "cristalizadas" e "convencionalizadas", as "regras semânticas" que regularizam o uso, a pragmática presta conta do que o falante expressou numa elocução, considerando a regra ou o violar dela, levando em conta mais do que foi dito explicitamente; dessa forma, a pragmática considera a dimensão do implícito, mesmo entendendo que o que foi dito explicitamente pode corresponder ao que foi pretendido e que nem todo tipo de implícito é pragmático por natureza (DASCAL, 2006, p. 36).

Segundo Dascal (2006), o contexto tem grande importância para a pragmática, tendo sido ele considerado, em outros tempos, a característica que melhor definiu a disciplina. Max Black (1971), citado por Dascal, propôs definir a pragmática como a ciência do contexto, nomeando-a contextics. Tal denominação deriva de suas funções comunicativas principais, já mencionadas, entre elas a do fornecimento de valores para preenchimento dos 'espaços em branco', presentes nas sentenças. Esses espaços são as variáveis livres que abrangem os inúmeros conjuntos de objetos contextuais; assim, "essa função do contexto fornece a informação necessária para passarmos do significado da sentença ao significado da elocução" (DASCAL, 2006, p. 42-43).

Além dessa função "complementadora", o contexto é a fonte principal de informação, a qual determina se a hipótese corresponde ou não ao significado do falante. Dessa forma, há uma necessidade, a priori, de estar ciente de algumas regras (do contexto) para poder interpretar semanticamente uma elocução. Dada uma informação, o contexto assume a função de fornecer pistas que gerem uma hipótese interpretativa alternativa, daí ocorre uma avaliação da aceitabilidade à luz dessa informação contextual (DASCAL, 2006, p. 43).

Conforme o autor, não se deve restringir "o contexto" a um conjunto de dados, mas estudá-lo de maneira funcional e organizada, como a fonte de informação responsável pelos "efeitos contextuais". O contexto "metalinguístico" inclui o "texto" ou "discurso", sendo o lócus onde a elocução a ser interpretada está inserida; esse tipo geral de contexto traz a ideia antiga de "contexto". O contexto "extralinguístico", de sua parte, adiciona informações sobre o "universo de referência" da elocução, remetendo às crenças, ao conhecimento de fundo, aos hábitos, às idiossincrasias, todos esses compartilhados pelos falantes e destinatários, incluindo, ainda, as circunstâncias especíicas da situação da elocução (DASCAL, 2006, p. 44).

Nesse artigo, elegemos dois teóricos que trabalham com o conceito e funcionamento do chiste. Pontuaremos o que dizem Dascal (2006) e Freud (1996b) sobre o chiste, trazendo uma contribuição aos trabalhos acadêmicos discursivos, especificamente para a área da 


\section{$=\mathrm{T} R A M A=$}

pragmática, da sociopragmática, da semântica, bem como, da psicanálise. Nossos objetivos são: 1. Abordar e discutir a teoria dascaliana e a freudiana em relação ao chiste; 2. Aplicar as teorias à análise dos chistes selecionados nesse artigo. O problema pontuado é quanto à possibilidade de encontrar pontos de convergência entre esses teóricos em seus discursos teóricos sobre o chiste, visto serem de épocas e áreas de estudo distintas. A hipótese é que o estudo de linguagem traz sempre uma condição interdisciplinar e multifacetada, portanto, pode permitir inúmeras possibilidades combinatórias. Assim, há enquanto hipótese, a possibilidade de uma harmonia de ideias, ou seja, um diálogo profícuo sobre o chiste entre as áreas do conhecimento selecionadas e representadas por Dascal (2006) e Freud (1996).

\section{A PRAGMÁTICA, O CONTEXTO E AS INTENÇÕES COMUNICATIVAS: DEFINIÇÕES CONFORME MARCELO DASCAL}

Com o propósito de definir pragmática, Dascal (1999) se apropria do que diz R. Carnap (1938), ao definir a semântica e a sintaxe como disciplinas teóricas e a pragmática como sendo tão-somente uma disciplina empírica. De acordo com esse autor, a pragmática não possui método próprio e se utiliza dos resultados de diferentes ramos da ciência, a dizer, da ciência social, da biologia, da psicologia, analisa a fisiologia dos processos dos órgãos da fala, do sistema nervoso ligado à fala e suas atividades, dentre outros ramos nos quais as investigações pragmáticas ocorrem (CARNAP, 1938, apud DASCAL, 2006).

Rudolf Carnap (1942) apoia-se numa tricotomia, anteriormente proposta por Charles Morris (1938), que de acordo com Levinson (1983, apud DASCAL, 2006), é vista como irrelevante e inconsistente para a pragmática atual:

se, em uma investigação, é feita uma referência explícita ao falante ou, em termos mais gerais, ao usuário da linguagem, então essa referência pertence ao campo da pragmática... Se nos abstrairmos do usuário da linguagem e analisarmos somente as expressões e aquilo que designam, estamos no campo da semântica. E se, por fim, nos abstrairmos também dos designata e analisarmos apenas as relações entre as expressões, estamos na sintaxe (lógica) (CARNAP, 1948, apud DASCAL, 2006, p. 28).

Carnap (1938) acrescenta observações a essa tricotomia que se constitui na base da pesquisa linguística, um ponto de referência importante devido aos problemas que ela suscita e à influência do modelo "residual" de definição do domínio da pragmática nela implícito. Dascal (1999) explicita dois desses problemas: 1. Com a eliminação dos falantes (condições de uso) torna-se possível desenvolver uma semântica e uma sintaxe das linguagens naturais independentes da pragmática; 2. A dissolução da pragmática em ciências diversas, privando-a de um objeto e método definidos (DASCAL, 2006).

Dascal (2006) pontua o que diz Chomsky (1975): quando a pragmática é concebida de maneira ampla, ela perde sua autonomia e coerência, é condenada a se tornar uma disciplina que versa sobre questões insolúveis, ou seja, não cientificamente solucionáveis (DASCAL, 2006, p. 29). Carnap (1938) "identifica a pragmática como o estudo que Saussure chamou de parole e Chomsky de performance". Assim, Dascal (2006) questiona a possibilidade de identificar um conjunto de fatores que delimitem a "essência" da atividade linguística (DASCAL, 2006, p. 30).

O problema da dissolução e da alegada falta de sistematicidade da pragmática está ligado ao modelo de definição de Carnap, que intitulei de 'residual'. Nesse modelo, a pragmática é definida como disciplina que lida com os fenômenos linguísticos com que as outras disciplinas linguísticas (principalmente a semântica) não têm obrigação de lidar. A fórmula de Gazdar (1979, p. 2), 


\title{
$=$ TRAMA $=$
}

'Pragmática = Significado menos Condição de Verdade', é um dos inúmeros exemplos da aplicação desse modelo. Ele sustenta que cabe à pragmática a responsabilidade de explicar os fenômenos do significado com os quais a semântica, concebida como teoria das condições de verdade dos enunciados, não se ocupa (DASCAL, 2006, p. 30).

Dascal (2006) discute essa ideia de a pragmática ser vista com função única de coleta dos fenômenos que foram desprezados por outras disciplinas que não tiveram tempo e ferramentas metodológicas necessárias ao estudo científico. O autor não aceita o modelo residual e pontua a necessidade de esforço para o desenvolvimento da pragmática em seu objeto e métodos, ou seja, cabe à pragmática explicitar fenômenos humanos importantes e merecedores de tal esforço (DASCAL, 2006).

Em seu trabalho, Dascal (2006) examina resíduos de outras teorias nas quais há possibilidade de ser encontrada a matéria-prima da pragmática. Em Bar-Hillel, há a ideia de "a cesta de lixo de Frege", ou seja, a ideia de que, para Frege, a semântica se envolve com "aspectos do significado relativos à verdade dos 'pensamentos' expressos nas sentenças" (Dascal, 2006, p. 31). Dascal diz que, o que foi descartado por Frege foi aproveitado pela pragmática no século $X X$, assim, houve resgate de um material rico, outrora descartado.

Frege (1967, apud Dascal, 2006, p. 32) considerou irrelevante, para os estudos semânticos, três tipos de sentenças: as que não levantam a questão da verdade (ordens, pedidos, promessas), as que exprimem mais que pensamentos (excitam sentimentos ou a imaginação) e as que não são suficientes para expressar um pensamento (expressões dêiticas). Esses fenômenos do significado, diz Dascal, foram tomados como objeto paradigmático da pragmática. A teoria dos atos da fala, a "lógica da conversação" de Grice, os estudos de Anscombre e Ducrot, o trabalho de Benveniste e os estudos de Bar-Hillel se ocuparam de aspectos que compõe o objeto que caracteriza a pragmática:

\begin{abstract}
cada uma dessas escolhas pressupõe o modelo residual de definição, pois ele caracteriza a pragmática como interessada em certos aspectos do significado que estão fora do domínio da semântica. Mas cada uma delas também pressupõe o seu próprio critério 'positivo', segundo o qual um fenômeno é concebido como pragmático se (a) estiver relacionado com a natureza do ato de fala executado ao proferir uma sentença; ou se (b) estiver relacionado com a 'diferença' entre o significado que uma elocução transmite o significado-padrão da sentença proferida; ou (c) depende não apenas da sentença, mas também do contexto no qual ela foi proferida. O que essas três concepções da pragmática enfatizam são três aspectos diferentes do uso da linguagem: (a) a ação linguística, (b) o significado implícito que pode ser inferido de tal ação e (c) o fato de esse significado ser dependente do contexto (DASCAL, 2006, p. 32).
\end{abstract}

Embasado em trabalhos de Grice, Dascal (2006) propõe como tarefa da pragmática estudar o uso dos meios linguísticos (ou outros) que o falante mobiliza para transmitir suas intenções comunicativas, a fim de que sejam reconhecidas pelo ouvinte: "o objeto da pragmática, portanto, é o conjunto de dispositivos semióticos direta e especificamente relacionados à transmissão dos significados do falante" (Dascal, 2006, p. 33). À semântica, cabe descrever ou explicar seu objeto de análise, pois a determinação do significado da sentença varia em seu uso. À pragmática, via falante, cabe explorar os significados da sentença e da elocução englobados nos dispositivos.

Dascal afirma que o falante de uma língua dada possui uma espécie de compreensão da compreensão, seja pré-teórica, pré-analítica ou intuitiva. Em função disso, o que é relevante para ele, não é construir, talvez, uma teoria, "mas compreender a natureza da compreensão, 


\section{$=$ TRAMA $=$}

mesmo que vozes de diversas escolas [teóricas] já tenham afirmado possuir essa compreensão" (DASCAL, 2006, p. 77-78).

Uma das teorias em voga (GRICE, 1957), segundo Dascal, defende que a compreensão de uma elocução requer que o ouvinte tenha capacidade de reconhecer a intenção do falante, apreendendo um determinado conteúdo e gerando um dado efeito. O autor (DASCAL, 2006) também menciona a recomendação, dada por Descartes, que sugeriu uma estratégia geral para obter a compreensão de uma questão complexa: "dividir cada uma das dificuldades examinadas no maior número de partes possível e da forma requerida para solucioná-las" (DASCAL, 2006, p. 82). Para Dascal, de certo, a análise é um pré-requisito para a compreensão, entretanto, restam - em sua ótica - alguns questionamentos:

se o objeto da compreensão for a própria compreensão, como poderemos decompô-la? Como reconhecer os seus verdadeiros componentes? E, principalmente, supondo que a compreensão envolve tanto uma fase analítica quanto uma sintética, qual é limite de ambas e como elas interagem? (DASCAL, 2006, p. 82).

Para esse autor, a compreensão na comunicação é sempre pragmática, pois não se trata de determinar o significado da sentença, nem de compreender as palavras em sua referência específica ao contexto da elocução, determinando-lhe o significado. Quando um significado do falante é transmitido diretamente há o "endosso" do significado da elocução pelo seu ouvinte, se identificado com as regras semântico-pragmáticas da linguagem. Entretanto, quando o significado é transmitido indiretamente, o significado pretendido se apresenta diferente do significado da elocução; neste caso, a interpretação pragmática busca descobrir o significado do falante, utilizando-se de pistas do contexto, tendo como ponto de partida o significado da elocução (DASCAL, 2006).

\section{O CHISTE COMO ATIVIDADE COMUNICATIVA}

\section{CONCEITO DE CHISTE CONFORME FREUD}

Em Os chistes e a sua relação com o inconsciente (1996[1905]), Freud analisa os chistes, buscando responder a questões do tipo: "Em que consiste, pois, a 'técnica' desse chiste? O que acontece ao pensamento, como expresso, por exemplo, em nossa versão, de modo a torná-lo um chiste que nos faz rir entusiasticamente?" (Freud, 1996b, p. 26). Os chistes podem liberar as nossas inibições, externalizando instintos agressivos, sexuais, de cinismo, etc., expressando-se conscientemente. Existem obras referentes ao humor anteriores à de Freud; entretanto, o autor apresenta o chiste como uma formação psíquica do inconsciente, destacando as dimensões do sentido e do desejo. Ele enfatiza apresentar a técnica dos chistes com estrutura semelhante aos mecanismos da condensação ${ }^{2}$ e do deslocamento ${ }^{3}$, pelos quais o inconsciente se apresenta nos sonhos. Aqui Freud aproxima um conteúdo ou termo, já conceituado sócio culturalmente, com a psicanálise. Associa a ação de expressar um chiste,

\footnotetext{
2 "A primeira coisa que se torna clara para quem quer que compare o conteúdo do sonho com os pensamentos oníricos é que ali se efetuou um trabalho de condensação em larga escala" (FREUD, 1996a, p. 305).

3 "O deslocamento do sonho e a condensação do sonho são os dois fatores dominantes a cuja atividade podemos, em essência, atribuir a forma assumida pelos sonhos. Não penso tampouco que teremos qualquer dificuldade em reconhecer a força psíquica que se manifesta nos fatos do deslocamento do sonho. A consequência do deslocamento é que o conteúdo do sonho não mais se assemelha ao núcleo do pensamento do sonho, e que este não apresenta mais que uma distorção do desejo do sonho que existe no inconsciente. [...] O deslocamento do sonho é um dos principais métodos pelos quais essa distorção é obtida" (FREUD, 1996a, p. 333-334).
} 


\section{$=$ TRAMA $=$}

em seu efeito cômico, com a intenção inconsciente de abreviar um pensamento contido, suprimido, através da condensação e/ou deslocamento. O autor considera a característica do chiste enquanto forma de expressão utilizada com poucas palavras, porém, que exerce a condição de dizer o intencionado, apesar de parecer insuficiente em termos utilizados. Essa brevidade, conforme Freud, é suficiente para expressar uma ideia análoga entre conteúdo recalcado e latente com uma situação em vivência, bem como, substituindo o primeiro (conteúdo) pelo segundo (situação).

Segundo Freud, o chiste é uma das formas de trânsito para que algo da ordem do recalcado abra passagem e se apresente.

De acordo com Lipps (1898), um chiste é algo cômico de um ponto de vista inteiramente subjetivo, isto é, algo que nós produzimos, que se liga a nossa atitude como tal, e diante de que mantemos sempre uma relação de sujeito, nunca de objeto, nem mesmo objeto voluntário (ibid., 80). Segue-se melhor explicação por um comentário de que o efeito daquilo, que, em geral, chamamos um chiste, é qualquer evocação consciente e bem-sucedida do que seja cômico, seja a comicidade devida à observação ou à situação (FREUD, 1996b, p. 17).

"A liberdade produz chistes e os chistes produzem liberdade", escreveu Jean Paul. Esse autor, citado por Freud (1996b), diz que o ato de fazer chistes é simplesmente jogar com as ideias. Ampliando, o chiste também é definido como a habilidade de encontrar similaridades entre coisas dessemelhantes, de descobrir similaridades escondidas. "Outras idéias, mais ou menos inter-relacionadas, que têm emergido para a definição ou a descrição dos chistes, são as seguintes: 'um contraste de idéias', 'sentido no nonsense', 'desconcerto e esclarecimento'” (FREUD, 1996b, p. 19). Em aproximação com a psicanálise, essa liberdade produtora ou que é produzida pelo chiste pode estar correlacionada ao conteúdo represado pelo inconsciente, assim, a liberdade de dizer, utilizando outras palavras por vias cômicas, libera tensões, forças catexizadas presentes no movimento, exercido pelo inconsciente, de reter o conteúdo latente.

Freud cita várias vezes Jean Paul (1804) e Lipps (1898) para falar sobre a brevidade como a essência, o corpo e a alma do chiste. A brevidade dos chistes é um aspecto significativo; um chiste diz o que tem a dizer "em palavras que são insuficientes do ponto de vista da estrita lógica ou dos modos usuais de pensamento e de expressão. Pode-se mesmo dizer tudo o que se tem a dizer nada dizendo" (FREUD, 1996b, p. 21). Aqui, entre o chiste e a relação com o conteúdo represado pelo inconsciente, a brevidade é caracterizante. Freud também trabalha com a nossa condição de desenvolver atos falhos ${ }^{4}$ enquanto produto do inconsciente, dessa forma, o autor sinaliza que os atos falhos são breves, rápidos, um dizer que é proferido com intenção encoberta de se falar sobre outra coisa. Logo, esses e os chistes, em suas formas sintéticas de expressão podem estar à serviço de um desejo inconsciente de externar o que incomoda, porém, que não foi percebido pelo indivíduo em sua consciência, ou que ainda não quer ser assumido e exposto pelo mesmo.

Jean Paul (1804) e Lipps (1898) atribuíram características bem definidas aos chistes: a atividade, a relação com o conteúdo de nossos pensamentos, a característica do juízo lúdico, a conjugação de coisas dissimilares, as ideias contrastantes, o 'sentido no nonsense', a

\footnotetext{
${ }^{4}$ Freud ressalta que os dados da consciência apresentam um grande número de lacunas. O autor entende essas lacunas como lembranças encobridoras, como os atos falhos, que só podem ser elucidados através do inconsciente. Freud evidenciou em suas teorias que o ato falho era como um sintoma, constituição entre o intuito consciente, o reprimido e a formação de compromisso - espécie de síntese entre dois desejos antagônicos. Através do ato falho, também cunhado pelo autor como lapsos de fala, o desejo do inconsciente é realizado. Sendo assim, o ato falho é um ato bem sucedido ao nível do inconsciente. "A ligação entre os chistes e os lapsos de fala também se evidencia no fato de que, em muitos casos, o deslize não passa de uma abreviação [...]" (FREUD, v. VI, p. 89).
} 


\title{
$=$ TRAMA $=$
}

sucessão de desconcerto e esclarecimento, a revelação do que estava escondido e a peculiar brevidade do chiste. Frente ao que esses autores sinalizam, é possivel perceber semelhanças características entre os chistes e a atividade mental inconsciente, visto que, essa atividade diz respeito aos fenômenos e conteúdos que não estão conscientes e, somente sob circunstâncias específicas, podem vir a ser um material disponível à consciência. Freud sempre afirma que parte da vida psíquica se desenvolve inconscientemente, assim, desejos e pensamentos humanos podem produzir conteúdos que causariam medo ao indivíduo, se não fossem armazenados no inconsciente. Assim, esse tem uma função importante de estabilização da vida consciente. Daí Freud afirma que chistes, atos falhos, sonhos, dentre outros, podem ser expressões simbólicas dos conteúdos produzidos pelo inconsciente.

Freud traz em seus estudos a prerrogativa de que conteúdos dolorosos ou traumáticos inconscientes podem influenciar a experiência consciente do indivíduo. Dessa forma, os chistes, os atos falhos, ou comportamentos aparentemente irracionais, emoções inexplicáveis, medo, depressão, sentimento de culpa podem manter uma correlação com esses conteúdos. Daí, Freud percebe adequação nas atribuições de características mencionadas por Jean Paul (1804) e Lipps (1898), afirmando que "parece-nos à primeira vista tão estritamente adequado e tão facilmente confirmável pelos exemplos, que não podemos correr qualquer risco de subestimar tais concepções" (FREUD, 1996b, p. 22). Vale exemplificar com um chiste constante do texto de Freud:

\begin{abstract}
e tão certo como Deus há de me prover todas as coisas boas, doutor, sentei-me ao lado de Salomon Rothschild e ele me tratou como um seu igual - bastante familionariamente (FREUD, 1996b, p. 25).

o processo pelo qual se forma o chiste ... pode ser descrito, nesse caso, como uma condensação acompanhada pela formação de um substituto; e no exemplo em pauta, a formação do substituto consiste na produção de uma palavra composta. Essa palavra composta 'familionar', que é em si mesma incompreensível, mas imediatamente compreendida em seu contexto e reconhecida como plena de sentido, é veículo do efeito compelidor do riso no chiste (FREUD, 1996b, p. 28).
\end{abstract}

Freud acrescenta, ainda, que há possibilidade de um pensamento ser expresso mediante formas linguísticas diversas; o chiste é uma delas, quando se pretende um efeito cômico envolvendo "desconcerto e esclarecimento". Assim, o pensamento expresso na sentença tem em si o caráter de um chiste, ou mesmo o chiste reside na expressão que o pensamento encontra na sentença (FREUD, 1996b). Em acréscimo, Freud (1996b) esclarece que há chistes que não apresentam as características destacadas por Jean Paul e Lipps: alguns não apresentam nonsense, ou "significados escondidos" ou "desconcerto e esclarecimento". Em alguns chistes, não há "contraste de ideias", ou contraste entre palavras e o que elas significam.

Alguns deles têm como característica única "o fato de que as mesmas palavras prestarem-se a usos múltiplos", ou seja, ocorre duplo sentido, jogo de palavras, o que pode ser constatado em três casos: (a) casos de duplo sentido do nome de uma coisa denotada no chiste; (b) duplo sentido procedendo dos significados literal e metafórico de uma dada palavra; (c) duplo sentido propriamente dito, ou jogo de palavras. Esse último caso pode ser descrito como caso ideal de "múltiplo uso" (FREUD, 1996b). A relação disso com a psicanálise encontrase na possibilidade de o indivíduo transpor o conteúdo inconsciente por meio de palavras em seus múltiplos usos, assim, a expressão chistosa ancorada em intenções encobertas e lacunares, por se respaldarem nesses conteúdos, podem aparecer por ambiguidades, no jogo dos termos ou dos significados literal e/ou metafórico. 


\title{
$=$ TRAMA $=$
}

\section{O EFEITO DO CHISTE DE ACORDO COM DASCAL}

Dascal (2006) desenvolve o capítulo dezesseis, da obra em estudo, voltado para compreender chistes e sonhos. Para tanto, o autor embasa-se em Freud e, a partir dele, Dascal expõe conceitos e associações, discutindo a relação dos chistes e dos sonhos na atividade comunicativa. Neste artigo, trataremos apenas dos chistes enquanto atividade comunicativa.

Respaldado em Freud, Dascal (2006) diz que o sonho não tem nada a comunicar, não tem a intenção de ser compreendido, sendo um produto mental associal. Já o chiste é social nas funções mentais e evoca prazer nos ouvintes; utilizando os processos mentais inconscientes, o chiste cria uma distorção não mais corrigida, sendo controlado pela condição de inteligibilidade, diferente dos sonhos (DASCAL, 2006). Nessa questão dos sonhos, não há concordância entre Dascal (2006) e Freud (1996a), pois, para o segundo, todo material que compõe o conteúdo de um sonho é derivado de experiências reproduzidas ou lembradas. Entretanto, a conexão entre o conteúdo de um sonho e a realidade não vem à luz facilmente, não há um resultado imediato da comparação entre ambos. A análise terapêutica, psicanalítica, pode contribuir para se perceber essa ligação de conteúdos que estão ocultos a muito tempo. Conforme autor, a razão disso está em diversas peculiaridades exibidas pela faculdade da memória nos sonhos (FREUD, 1996a).

Quanto aos chistes, Dascal (2006) conceitua como atividade comunicativa, estando eles sujeitos às limitações gerais que regulam os usos comunicativos da linguagem. Essas limitações constituem o objeto de investigação da sociopragmática; assim, a função de dar prazer por meio dos chistes estabelece a mediação com o entendimento de um dado ouvinte/leitor, apresentando propriedades específicas que interessam à pragmática. Aqui há uma concordância conceitual com o que diz Freud, isso sinaliza uma parceria não forçada com a pragmática no que tange ao chiste.

\begin{abstract}
Como observa o próprio Freud, o chiste é uma atividade essencialmente social. Isso significa que a sua intenção é produzir prazer em um ouvinte. Além do mais, essa intenção é uma intenção comunicativa. Ou seja, ela funciona por intermédio do reconhecimento do ouvinte da intenção do falante. A risada produzida pelo ato de fazer cócegas deve ser diferenciada da risada produzida por um chiste. No primeiro caso, a intenção da pessoa que faz cócegas não é comunicativa e, portanto, não requer o reconhecimento do ouvinte. A intenção é realizada por um mero processo causal. No segundo caso, o processo causal precisa do reconhecimento da intenção do falante pelo ouvinte. Ou seja, é mediado pela consciência (DASCAL, 2006, p. 383-384).
\end{abstract}

Dessa forma, Dascal (2006) sinaliza a intenção comunicativa do chiste, apontando para o caminho da consciência, o qual media o processo de reconhecimento da intenção. Freud diz sobre essa intenção de uma outra forma, se apropriando de diferentes técnicas, organizandoas em grupos: no primeiro, ele diz que o chiste pode ocorrer pela condensação através da formação de palavras compostas ou pela modificação; no segundo, acontece pelo múltiplo uso do mesmo material, com o todo e suas partes, em ordem diferente, com leve modificação ou com sentido pleno ou esvaziado; por fim, no terceiro, Freud diz que o chiste pode acontecer através do duplo sentido, neste, o significado pode ocorrer como um nome ou coisa, metafórico ou literal, duplo sentido enquanto jogo de palavras, double entendre, ou como uma alusão (FREUD, 1996b). Percebe-se, então, que a abordagem dos dois teóricos sobre o chiste, traz pontos de convergência quanto a intenção comunicativa. O caminho de bifurcação é quanto ao processo de consciência, abordado por Dascal, e do inconsciente, amplamente discutido por Freud em todos os seus trabalhos, inclusive sobre o uso dos chistes. Entretanto, a intenção de comunicar, de dizer, de expressar o que está na superfície do pensamento ou em sua 


\section{$=$ TRAMA $=$}

profundidade, encoberto, é uma necessidade humana. Essa intenção pode acontecer de formas variadas, direta ou indireta, pelo uso de poucas ou muitas palavras, até mesmo nas ausências e silenciamentos delas.

Dascal (2006) afirma que o quadro (frame) do chiste envolve a produção do riso pelo recurso do enquadramento. O sucesso do processo de comunicação verbal está relacionado à interação da semântica com a pragmática, ou seja, o destinatário deve reconhecer as especificidades embutidas no material linguístico do chiste. Para o autor, o discurso transmite uma interpretação pragmática, mas o sucesso da comunicação depende da capacidade de interpretação do destinatário (DASCAL, 2006). Aqui há uma correlação com o posicionamento freudiano em relação a técnica escolhida ao utilizar um chiste, pois, seja pela condensação, pelo múltiplo uso de palavras ou pelo duplo sentido, há interação com a semântica e com a pragmática. Ou seja, a intenção comunicativa do produtor do chiste, além de expressar conteúdo consciente e inconsciente, apenas promove o riso, pragmaticamente, se o enquadramento fizer sentido ao destinatário.

A indiretividade desempenha um papel crucial nos chistes e é explorada sistematicamente, visto que os recursos pragmáticos permitem esse uso; consequentemente, a indiretividade provoca um efeito de "bissociação". O material verbal do chiste dá margem a uma série de interpretações e o ouvinte/leitor aproxima-se da melhor delas, porém, não lhe é dada uma indicação explícita. Há a interpretação alternativa e a preferencial; o ouvinte/leitor contribui mais para a segunda do que o próprio falante. O ouvinte/leitor forma a interpretação preferencial enquanto ouve/lê o chiste, esperando que o resto da história confirme sua interpretação: "o efeito cômico surge quando uma interpretação alternativa, não preferencial e, portanto, não esperada revela-se no final do chiste como sendo a correta" (DASCAL, 2006, p. 385).

Em uma das abordagens freudianas no que se refere à formação ou técnica do chiste, a condensação é apresentada como uma "aglomeração" de ideias que tem pontos em comum, analogicamente. Assim, a condensação é acompanhada pela formação de um substituto que consiste na produção de uma palavra composta, a qual pode ser compreendida em seu contexto e reconhecida em seu sentido (FREUD, 1996b). Aqui é possível sinalizar uma aproximação com o pensamento dascaliano em relação a indiretividade presente no chiste, pois o efeito de "bissociação" que ela provoca está ligado ao encontro de ideias, de pontos em comum. Por um lado, a intenção consciente ou inconsciente, por outro, a expressão escolhida pelo produtor do chiste que melhor traduz seu desejo de dizer provocando o riso, o prazer, considerando o contexto e o sentido para quem diz/escreve e para quem ouve/ler.

Dascal (2006) defende a ideia de que a eficiência dos chistes depende da existência de recursos sociopragmáticos, pois tornam possíveis a indiretividade e a implicitude. Dascal afirma que o próprio Freud enfatizou a importância de pistas parcimoniosas, dedicando atenção ao que chamou de "representação indireta". Esses recursos pragmáticos produzem efeitos cômicos; entretanto, o requisito da "inteligibilidade" (também mencionado por Freud), ou seja, o domínio dos recursos sociopragmáticos de um chiste, é que possibilita a transmissão da indiretividade "e requer que o contador do chiste faça um uso sensato desses recursos, tomando em consideração o conhecimento de fundo background da plateia, sua compreensão pragmática, etc." (DASCAL, 2006, p. 387). Assim, ambos autores trabalham com o chiste numa perspectiva aproximada, sinalizando a condição humana de intenção comunicativa através do recurso chistoso, o qual exige requisitos específicos como a inteligibilidade, a implicitude (consciente ou inconsciente), a indiretividade, o agrupamento de ideias que respeita o contexto e a formação de sentido. 


\section{$=$ TRAMA $=$}

\section{ANÁLISE DE TRÊS CHISTES DIRECIONADOS À MULHER: INDIRETIVIDADE E INTENCIONALIDADE}

Dascal (2006) pontua que as análises perspicazes de Freud dão uma dimensão do quanto se pode ir além com relação à "compreensão" dos chistes, numa tentativa de descobrir o motivo da liberação de energia provocada por ele, como o riso: "para isso entra-se no domínio dos desejos, motivos etc. (inconsciente), que funcionam independentemente das intenções (conscientes, comunicativas) tanto do ouvinte quanto do contador do chiste" (DASCAL, 2006, p. 388).

Sendo o chiste uma das formas de linguagem utilizadas cotidianamente, no cenário político, é possível perceber inúmeros deles, em circulação: "Certamente mandou para o presidente Putin e certamente o Putin ficou meio 'putin' com o Brasil"; este foi um chiste proferido pelo ex-presidente Lula, em 2007, fazendo referência ao contexto em que o presidente russo teria recebido a notícia de que os frigoríficos brasileiros estariam pagando suborno a autoridades russas para continuar exportando. Outro exemplo: "relaxa e goza porque você vai esquecer todos os transtornos", chiste dito por Marta Suplicy sobre a crise aérea em 2007, quando era Ministra do Turismo. "O Palácio dos Bandeirantes é como uma colmeia, metade fica voando e metade fica fazendo cera", foi outro chiste produzido pelo deputado federal Paulo Maluf sobre o governo de Franco Montoro, em São Paulo, nos anos 80.

Por meio do presente artigo, buscou-se analisar três chistes direcionados à mulher, em contextos políticos. A escolha desses chistes se deu pelo motivo de a autora do artigo já estar trabalhando com algumas matérias que falam sobre o contexto sociocultural e educacional da mulher, em alguns ambientes específicos. Logo, escolher três chistes direcionados à mulher foi devido a aproximação com a temática em estudo no momento de produção do artigo.

Em 2007, o deputado Clodovil Hernandes (PTC-SP) proferiu o seguinte chiste: "Hoje em dia, uma mulher trabalha deitada e descansa em pé" (FERRARE; FERRAZ; TORRES, 2007). Certamente, o deputado distorceu e escondeu o motivo latente do dizer, entretanto, por ter proferido o chiste num ambiente público da tribuna da Câmara, foi solicitada uma explicação. O político buscou formas para atenuar o motivo latente e distorcido, afirmando que não desejava ofender as mulheres. Porém, analisando a composição do chiste, é possível perceber que o conteúdo perpassa a ideia de associar a mulher ao ato sexual. Em suas tentativas de atenuar o dito devido às pressões, Clodovil afirmou que "disse isso para defender as mulheres, porque não me digam que uma moça que vai fazer filme pornô pode servir de referência na televisão". Essa explicação confirma a associação distorcida da mulher, enquanto praticante do ato sexual remunerado, ou não, mas, na certa, alude a uma das atividades cotidianas correlacionada à palavra 'trabalho'.

O chiste distorce e esconde os motivos latentes, porém, estes, ao serem reconhecidos, determinam uma interpretação psicanalítica que chega a camadas mais profundas da significância não atingidas apenas em nível comunicativo. Nesse sentido, entre o que diz Dascal (2006) e Freud (1996b) sobre chiste enquanto recurso comunicativo, pode-se afirmar que no chiste o funcionamento pragmático ocorre, também, no ato de se sentir satisfeito. Ou seja, existe no produtor do chiste uma intenção indireta de dizer algo que se encontra latente em seu pensamento, há um desejo de satisfação mediante o ato de se expressar, assim, esse se satisfazer enquanto gozo é expresso na construção do chiste e na suposta intenção de provocar o riso frente a sua recepção inteligível. Dascal (2006) atesta isso ao dizer que,

[...] os desejos e motivos inconscientes são satisfeitos, mediante o chiste, por meio do que ele é capaz de comunicar. Isto é, a sua satisfação é mediada por um processo de comunicação e compreensão no nível linguístico. Pode-se dizer que 


\section{$=$ TRAMA $=$}

o nível linguístico é o veículo pelo qual os desejos mais profundos são expressos e satisfeitos (DASCAL, 2006, p. 388).

O nível linguístico utilizado pelo deputado foi "mulher trabalha deitada"; essa expressão é o veículo condutor do desejo profundo não expresso, portanto, a indiretividade é o indício da fonte de satisfação e realização do conteúdo latente ${ }^{5}$. Para Freud (1996b), há vários tipos de representação indireta utilizada pelos chistes, dentre elas, a alusão e a analogia. Quanto à primeira, o autor diz ser o método mais comum e facilmente controlável, estando presente na maior parte dos chistes proferidos nas conversações. Já a segunda, suscita dúvida ao se buscar perceber a natureza essencial de uma analogia chistosa. Assim, na construção do chiste, Clodovil utiliza a representação indireta analógica, pois, enquanto resultado dela, há uma representação pelo absurdo que advém de um processamento psíquico.

Dessa forma, o 'veículo' não é apenas acessório; a 'forma' do chiste a qual the dá expressão não pode estar separada dele, pois ao 'reduzir' um chiste a uma 'mensagem' (forma linguística) ele deixa de ser um chiste; "O trabalho de interpretar um chiste consiste exatamente em sintetizar essa forma, de modo a produzir o efeito desejado" (DASCAL, 2006, p. 388). O chiste, portanto, produz criativamente um trecho de discurso com sua intenção comunicativa em adequação, ao propósito de ser reconhecido pelo destinatário. No trecho de discurso, produzido no chiste do deputado Clodovil, houve o reconhecimento da intenção comunicativa por parte da plateia que, supostamente, foi motivada a rir, ou a sentir aversão e conflito.

Logo, o chiste explora os princípios sociopragmáticos do uso da linguagem, permitindo a transmissão de mensagens indiretas ou implícitas, através de meios diversificados. Cabe à plateia interpretar as pistas indiretas. A indiretividade ou implicitude é assunto de debate, sendo entendida por alguns autores como ambiguidade (ZIJDERVELD, 1983, apud Dascal, 2006, p. 389). De fato, é por meio dos recursos da indiretividade que o chiste chama a atenção do destinatário, tipificando um uso sociopragmático da linguagem (DASCAL, 2006). Assim, a indiretividade pode funcionar como um recurso adicional de deslocamento; no caso do chiste em análise, o deslocamento se encontra na expressão "trabalhar deitada". Anterior à expressão, o deputado contextualiza seu ato discursivo assinalando à época a que ele remete sua assertiva: "Hoje em dia". A seguir, ele desloca a ideia dos tipos/formas de trabalho para a indiretividade da prática sexual, externando conteúdos inconscientes que respaldam suas intenções ou concepções.

Dascal (2006) afirma que o chiste é um texto em que devem coexistir pelo menos dois níveis de significado, distintos e opostos, sendo que, o significado literal deve estar "localizado" no "horizonte de atenção". Para processar a compreensão do chiste, o significado "literal" ou "primário" deve estar disponível ao ouvinte, mesmo que o significado "metafórico" seja o dominante (DASCAL, 2006, p. 592). No chiste proferido por Clodovil, o sentido primário se ancora na ideia de trabalho e de esforço, porém o significado dominante, desejável pelo seu proferidor, é o sentido depreciativo atribuído pelo locutor à mulher, sendo este o elemento latente de responsabilizar a mulher pelos atos de leviandade ou prostituição, por interesse ou deleite.

Outro dado selecionado para análise ocorreu em abril de 2016. A Revista Isto É editou uma matéria intitulada "Uma presidente fora de si" para retratar, conforme a revista, a situação política em que se encontrava o país. A revista afirma que os bastidores do Planalto, naqueles dias, mostravam que a iminência do afastamento fez com que Dilma perdesse o equilíbrio e as

\footnotetext{
5 "O reprimido é, para nós, o protótipo do inconsciente. Percebemos, contudo, que temos dois tipos de inconsciente: um que é latente, mas capaz de tornar-se consciente, e outro que é reprimido e não é, em si próprio e sem mais trabalho, capaz de tornar-se consciente" (FREUD, 1996c, p. 28).
} 


\section{$=$ TRAMA $=$}

condições emocionais para conduzir o País. Buscando consolidar a ideia, os editores Sérgio Pardellas e Débora Bergamasco dizem que, em estado de descontrole, a presidente se entope de calmantes desde quando a crise iniciou. Num tom de crítica, afirmam que nem sempre os medicamentos surtem efeito:

os últimos dias no Planalto têm sido marcados por momentos de extrema tensão e absoluta desordem com uma presidente da República dominada por sucessivas explosões nervosas, quando, além de destempero, exibe total desconexão com a realidade do País. Não bastassem as crises moral, política e econômica, Dilma Rousseff perdeu também as condições emocionais para conduzir o governo. Assessores palacianos, mesmo os já acostumados com a descompostura presidencial, andam aturdidos com o seu comportamento às vésperas da votação do impeachment pelo Congresso. Segundo relatos, a mandatária está irascível, fora de si e mais agressiva do que nunca. Lembra o Lula dos grampos em seus impropérios. Na última semana, a presidente mandou eliminar jornais e revistas do seu gabinete. Agora, contenta-se com o clipping resumido por um de seus subordinados. Mesmo assim, dispara palavrões aos borbotões a cada nova e frequente má notícia recebida. Por isso, os mais próximos da presidente têm evitado tecer comentários sobre a evolução do processo de impeachment. Nem com Lula as conversas têm sido amenas. Num de seus acessos recentes, Dilma reclamou dos que classificou de 'traidores' e prometeu 'vingança'. Numa conversa com um assessor, na semana passada, a presidente investiu pesado contra o juiz Sérgio Moro, da Lava Jato. 'Quem esse menino pensa que é? Um dia ele ainda vai pagar pelo quem vem fazendo', disse. Há duas semanas, ao receber a informação da chamada 'delação definitiva' em negociação por executivos da Odebrecht, Dilma teria, segundo o testemunho de um integrante do primeiro escalão do governo, avariado um móvel de seu gabinete, depois de emitir uma série de xingamentos. Para tentar aplacar as crises, cada vez mais recorrentes, a presidente tem sido medicada com dois remédios ministrados a ela desde a eclosão do seu processo de afastamento: rivotril e olanzapina, este último usado para esquizofrenia, mas com efeito calmante. A medicação nem sempre apresenta eficácia, como é possível notar (REVISTA ISTO É, 2016).

Em contrapartida, Dilma Rousseff avalia a nota editorial como misoginia. Para ela, "é um texto muito baixo, que reproduz um tipo perverso de misoginia para dizer que quando uma mulher está sob pressão costuma perder o controle". Em cerimônia no Palácio do Planalto com mulheres em defesa da democracia, a presidente classifica a matéria como "peça de ficção" para "me ofender justamente por ser mulher. A revista levantou que eu reajo com descontrole. Então, a mulher só tem duas opções, ou ela é autista ou é descontrolada" (ROUSSEFF, 2016).

Considerando o conceito de misoginia, é possível pontuar que a edição da revista citada atribui características ofensivas à pessoa da presidente: "dominada" por sucessivas explosões nervosas, "destempero", exibe "total desconexão" com a realidade do País, "perda das condições emocionais" para conduzir o governo e outras. Esses são diagnósticos formalmente feitos por profissionais das áreas psicológicas e neurológicas, não sendo permissíveis eticamente a editores jornalísticos, a quem não cabe de ofício fazer tais tipos de avaliação.

Ao afirmar que as palavras contidas na Revista Isto $E$ eram um tipo perverso de misoginia, Dilma Rousseff, de sua parte, levanta questões referentes ao respeito devido a todo tipo de diferença. Mesmo com todas as acusações que estavam sendo-Ihe atribuídas no campo político, naquela instância, não the parecia coerente que alguém a tratasse como descontrolada; assim, afirmava que aquelas 'acusações' estavam também sendo influenciadas pelo fato de ela ser mulher.

Dessa forma, fica evidente que, mesmo após tantos anos de luta em prol de um deslocamento e de busca de um lugar de pertencimento, a mulher ainda se sente ofendida com alguns discursos e ações que traduzem ranços milenares presentes em sociedades e culturas da atualidade. O processo identitário de gênero vem tomando seu curso na história e ocupando 


\section{$=$ TRAMA $=$}

lugares nos ambientes discursivos. Ao afirmar que o discurso da revista em questão era um tipo perverso de misoginia, Dilma pressupunha que o público de mulheres que a ouvia/lia tinha consciência de parte dos ranços e avanços que envolviam a luta das mulheres, bem como demarcava uma continuidade da defesa ideológica de um grupo de pessoas, envolvendo liberdade de escolha e respeito às mulheres.

Pontuamos como chiste a expressão da ex-presidente, pois apresenta uma forma de liberar uma inibição, externando um pouco do seu instinto agressivo. O chiste produzido por ela reside na forma de manifestação que o pensamento encontrou através da expressão: "descontrolada ou autista", encontrando similaridade entre coisas dessemelhantes e descobrindo similaridades escondidas, porém ditas indiretamente. Assim, o pensamento da expresidente foi expresso e representado através de uma forma particular de dizer, que podia até ser estranha à plateia, porém esse processo de conversão do pensamento em um chiste é comumente interpretável com facilidade pelos ouvintes. O chiste formado com as palavras "descontrolada" e "autista" estão substituindo o não dito, em resposta ao dito pelos editores da revista.

O elemento latente presente na expressão "autista", em oposição à "descontrolada", indica a possibilidade de a mulher estar/permanecer submissa às ideias patriarcais, alheia às reivindicações e representações femininas necessárias às lutas de gênero, dentre outras. Ao produzir o chiste, Dilma usou uma maneira criativa de linguagem, criada conscientemente, porém com possibilidades de origem inconsciente. Nesse sentido, nos apropriando do que diz Dascal (2006), "a linguagem é usada de maneira criativa porque, apesar das suas origens inconscientes, o chiste é na verdade criado pelo consciente" (DASCAL, 2006, p. 398).

Outro chiste aqui analisado foi proferido pelo último presidente dos Estados Unidos, na época das eleições americanas. Ele foi questionado quanto à crítica feita à âncora do canal Fox, Megyn Kelly, durante e após o debate de republicanos, ocorrido em agosto de 2015. Perguntado sobre Kelly em uma entrevista da CNN, Trump disse: "Era possível ver sangue saindo dos olhos dela. Sangue saindo de qualquer lugar... Você podia ver que ela estava fora de controle". Segundo a editora da matéria, durante o debate, Megyn Kelly bombardeou Trump com perguntas sobre suas atitudes sexistas, como ter chamado algumas mulheres de "porcas gordas, cachorras" e outros nomes de animais (SCHIBUOLA, 2015). Neste artigo, interessa pontuar o chiste produzido por Trump em seu discurso: "saindo sangue de qualquer lugar...".

É possível dizer que o chiste em análise traz o que Freud atesta: "uma condensação acompanhada de um substituto" (FREUD, 1996b, p. 28). A condensação decorre do resumo de ideias que têm pontos em comum, ocorrendo uma analogia. Além da condensação, há também um deslocamento em que um elemento latente é substituído por um dos fragmentos constituintes. Para entender o resumo das ideias com pontos em comum, necessário se faz ampliar o entendimento pela via sociopragmática, ou seja, contextualizar o discurso e o lugar de fala do locutor.

A partir dessa perspectiva, é relevante dizer que este chiste foi produzido por um falante que costuma proferir discursos considerados misóginos: "As mulheres são, na essência, objetos estéticos agradáveis"; "A beleza e elegância de uma mulher, de um edifício ou de uma obra de arte é, apenas, qualquer coisa de superficial, ou de bonito para se olhar"; "As agressões sexuais no exército são algo totalmente previsível"; "6000 agressões sexuais não relatadas nas forças armadas, apenas 238 tiveram sanções. O que se esperaria de diferente quando a gente mistura homens e mulheres?"; "Na TV, as mulheres têm que se utilizar do seu sex appeal"; "As más notícias que lhe dizem respeito não são importantes - desde que você tenha uma esposa sexy"; "Sabe, não vale a pena dar crédito ao que diz a mídia quando você tem ao seu lado um 'tesouro' jovem e atraente" (RIESTRA, 2016). 


\section{$=$ TRAMA $=$}

A relação de observações de Trump, contida no parágrafo anterior, evidencia que conceber que o chiste "saindo sangue de qualquer lugar" contém pontos em comum com o conceito de mulher, tal qual implícito nas mensagens cotidianas desse falante, em especial, é algo previsível. Na observação considerada, há a mensagem implícita de que a mulher é acometida de hábito por sangramentos biológicos, metafóricos ou analógicos. Essa interpretação pode ser dada considerando-se a substituição de uma palavra com sentido direto (talvez referente à ideia patriarcal de menstruação como castigo predestinado ao feminino, ou pelo sentido repugnante atribuído ao sangue e associado à mulher) pelo fragmento "saindo sangue de qualquer lugar" (sangue enquanto elemento que se relaciona à raiva, a descontrole, a algo que é expelido do corpo feminino).

Considerando-se as falas misóginas de Trump, o elemento latente, deslocado para o fragmento, seria o conceito depreciativo de mulher, formulado em suas mensagens indiretas, agressivas e críticas associadas ao mau humor. Essa análise pode ser feita considerando-se a via sociopragmática discutida no presente artigo (DASCAL, 2006). Sinalizando o que afirma Freud (1996b) sobre a analogia, esta é um tipo de representação indireta utilizada pelos chistes por conter uma singular justaposição de ideias (combinação aparentemente absurda) ou por ser substituível por algo semelhante ao resultado da analogia, considerando a analogia chistosa como material de suas investigações. Logo, ao caracterizar a expressão de Trump como chiste, isso não ocorreu pelo requisito de provocar o riso, pois suas falas misóginas são mais causadoras de indignações e não concordância. Pontuamos como chiste pelos critérios, respaldados em Dascal (2006) e por Freud (1996b), da indiretividade, intencionalidade e pela satisfação do produzente em externar um desejo inconsciente, abreviando um pensamento contido, suprimido, através da condensação e do deslocamento. Foi uma forma que ele encontrou para expressar sua ideia análoga entre conteúdo recalcado e latente com uma situação em vivência, substituindo o conteúdo pela situação.

Em suma, elegemos dois teóricos que trabalham com o conceito e funcionamento do chiste para construção desse artigo. Nele, buscamos sinalizar partes do que dizem Dascal (2006) e Freud (1996b) sobre o conteúdo em questão, em contribuição aos trabalhos acadêmicos discursivos de algumas áreas, especificamente, da pragmática, da sociopragmática, da semântica, bem como, da psicanálise. Nosso objetivo se estendeu a, além de discutir a teoria, aplicá-la à análise dos chistes selecionados neste artigo. Nossa problemática foi correspondida na mesma medida que nossa hipótese foi confirmada; isso devido a possibilidade de pontuar o entrelace discursivo entre os dois teóricos, demarcando uma harmonia de ideias. Assim, pontuamos o ineditismo do nosso trabalho. Apesar de serem de épocas e áreas distintas, no entrelace, percebemos que ambos trazem em seus discursos teóricos a questão da intenção comunicativa dos chistes a partir da indiretividade e da intencionalidade em busca de uma satisfação consciente ou inconsciente, permissível no ato chistoso. Logo, o funcionamento pragmático do chiste, nesse trabalho, pode estar interligado a questões inconscientes, as quais mantém influência na formação consciente do pensamento.

\section{CONSIDERAÇÕES FINAIS}

A produção deste artigo possibilitou o diálogo entre áreas do conhecimento, a dizer: a pragmática e a psicanálise. Buscou-se entender o conceito e a aplicabilidade do chiste sob a ótica de Dascal (2006) e de Freud (1996). Para tanto, houve a necessidade de itinerar pelo que diz o primeiro autor sobre pragmática, interpretação/compreensão leitora e intenção comunicativa.

As análises dos três chistes referentes à mulher, produzidos em contextos políticos, foram uma tentativa de aplicação da teoria freudiana e dascaliana a atos de fala cotidianos, 
atestando que o estudo de linguagem é interdisciplinar, multifacetado, envolvendo inúmeras possibilidades combinatórias. Logo, torna-se válido demarcar enquanto considerações que, "é quase impossível atravessar uma multidão portando a tocha da verdade sem chamuscar a barba de alguém" (FREUD, 1996b, p. 84). Em outra forma dizer, parafraseando, é impossível atravessar uma multidão portando a tocha da linguagem sem clamar pelo dizer interdisciplinar.

\section{REFERÊNCIAS}

DASCAL, Marcelo. Interpretação e compreensão. Tradução Marcia Heloisa Lima da Rocha. São Leopoldo, RS: UNISINOS, 2006.

FERRARE, Carol.; FERRAZ, Lucas.; TORRES, Rodolfo. Clodovil no centro da polêmica. Congresso em Foco. Abril, 2007. Disponível em: http://congressoemfoco.uol.com.br/noticias/clodovil-no-centro-da-polemica/ . Acesso em: 12 jul. 2017.

FREUD, Sigmund.Obras psicológicas completas de Sigmund Freud: A interpretação dos sonhos (I) (1900). v. IV. Tradução sob direção geral de Jayme Salomão. Rio de Janeiro: Imago editora, 1996a.

FREUD, Sigmund. Obras psicológicas completas de Sigmund Freud: Os chistes e a sua relação com o inconsciente (1905). v. XIII. Tradução sob direção geral de Jayme Salomão. Rio de Janeiro: Imago editora, 1996b.

FREUD, Sigmund.Obras psicológicas completas de Sigmund Freud: O ego e o id e outros trabalhos (19231925). v. XIX. Tradução sob direção geral de Jayme Salomão. Rio de Janeiro: Imago editora, 1996c. Revista Isto É. Uma presidente fora de si. 2016. Disponível em: http://istoe.com.br/450027_UMA+PRESIDENTE+FORA+DE+SI/ . Acesso em: 5 jun. 2020.

RIESTRA, Laura. 18 coisas que Donald Trump disse sobre as mulheres. Esquerda Diário. Novembro, 2016. Disponível em: http://www.esquerdadiario.com.br/18-coisas-que-Donald-Trump-disse-sobre-as-mulheres.

Acesso em: 10 jul. 2020.

ROUSSEFF, Dilma. Cerimônia Palácio do Planalto. 2016. Disponível em: https://pt.scribd.com/document/310974365/Capa-Da-IstoE-e-Baixa-e-Reproduz-Misoginia . Acesso em: 25 mai. 2020.

SCHIBOULA, Tatiana. Declaração infeliz de Donald Trump irrita femininistas (e qualquer mulher que já tenha ouvido que sua assertividade era, na verdade, TPM). Revista Cláudia, agosto, 2015. Disponível em: http://claudia.abril.com.br/noticias/declaracao-infeliz-de-donald-trump-irrita-femininistas-e-qualquer-mulherque-ja-tenha-ouvido-que-sua-assertividade-era-na-verdade-tpm/. Acesso em: 13 jul. 2020.

Recebido em 30-10-2020

Revisões requeridas em 30-11-2020

Aceito em 29-12-2020 